\title{
Linking nurses' attitudes and behaviors to organizational values: implications for human resource management
}

\author{
Jillian Cavanagh \\ LaTrobe University, Melbourne, Victoria, Australia \\ RON FISHER \\ Griffith University, Gold Coast, Queensland, Australia \\ MARK FRANCIS \\ Cardiff Metropolitan University, Cardiff, UK \\ ROD GAPP \\ Griffith University, Gold Coast, Queensland, Australia
}

\begin{abstract}
The researchers use established measures of job satisfaction (JS) and organizational citizenship behavior (OCB) to analyze data obtained from nurses in an Australian hospital $(n=573)$, and to discuss implications for human resource management. In this study the researchers seek to understand the links between nurses' JS, OCB and their perceptions of the values espoused by the organization. Changes in JS and OCB as length of service increases are also examined. Findings suggest that JS and OCB are both significant predictors of nurses' perceptions of organizational values. The findings also suggest that nurses more readily internalize organizational values when levels of JS and $O C B$ are high. A further finding is that the tendency to engage in $O C B$ declines significantly as length of service increases.
\end{abstract}

Keywords: human resource management, nurses, job satisfaction, organizational citizenship behavior, values, length of service.

\section{Introduction}

In this study the researchers address a significant human resource management (HRM) dilemma in the healthcare sector: how to sustain key healthcare workers such as nurses to ensure that they have positive perceptions of values espoused by the organization? In hospitals, interaction between nurses and stakeholders has always been critical in determining whether patients experience satisfaction or dissatisfaction in the provision of healthcare (Zangaro \& Soeken, 2007). Organizational values that lead to the provision of quality service have clear links with frontline staff such as nurses. Employee attitudes and behaviors are important factors in service encounters, with committed employees experiencing increased motivation and satisfied employees linked with increased levels of customer satisfaction (Ballout, 2007). Organizational citizenship behavior also plays an important part in health service encounters by allowing nurses the discretion to respond to the needs of patients, particularly needs which are outside the conventional scope of an employee's work (Organ, Podsakoff \& MacKenzie, 2006). The importance of employee attitudes and behaviors in service delivery reinforces the need to investigate the linkages between employee JS and OCB, and their impact on organizational values (Lu, While \& Barriball, 2005).

Changes in the workplace, together with the growing intensity of work, mean that work practices are constantly changing and organizations need effective processes to accommodate 
such changes (Bellou, 2010). Within an environment of constant flux maintaining employee satisfaction poses a challenge to most organizations. In conditions of rapid change there is a growing need to examine 'what is really going on' within the organization to ensure its very survival. The aim of this study is to understand the links between JS, OCB, organizational values, and length of service. Understanding the links between JS, OCB, organizational values, and length of service in a hospital setting will add to the body of knowledge relating to caregivers' attitudes and behaviors and could have important implications for HRM practice.

The article is organized as follows: (a) first the literature relating to JS, OCB and organizational values is reviewed and summarized; (b) then research methods, data collection and data analysis are discussed; and (c) finally the results are discussed along with implications for HRM in healthcare and opportunities for further research.

\section{Recent Research in Employee Attitudes and Behaviors}

Hospitals' management groups are becoming more concerned with the governance, profitability and sustainability of hospitals as work sites for effective patient care as well as critical teaching facilities for contemporary medical students. Essentially, effective patient care is about ensuring quality of service and patient safety (Fraenkel \& McGraw, 2007). Other professional caregivers (e.g. nurses) negotiate their roles to comply with organizational policies and practices in providing expertise in support of patients and physicians. How nurses perceive their roles is important to the raison d'être for a hospital's very existence, namely the best of patient care. The literature presented here considers job satisfaction, organizational citizenship behaviors, organizational values and the dynamics of these areas. The rationale is to establish links between JS, OCB, and staff perceptions of values espoused by the organization that will assist management to enhance opportunities to achieve organizational outcomes more effectively.

Job satisfaction

Job satisfaction is most frequently understood to be "a pleasurable or positive emotional state resulting from the appraisal of one's job" (Locke, 1976, p. 1300). Fundamentally, job satisfaction is a positive response proportionate to the degree to which an individual enjoys his or her job (Lu et al., 2004). Job satisfaction is dependent upon the kind of job and also each individual's expectations of what that job will bring, both intrinsically and extrinsically. Intrinsic job satisfaction has an affective basis, that is it captures how people feel about their jobs, and is associated with job involvement. Extrinsic motivation can be explained by the results of a definite activity such as work and remuneration as the reward for such work (Hirschfeld, 2000). Developing a better understanding of job satisfaction is a critical factor in understanding the attitudes and behaviors of employees, as well as gauging organizational effectiveness (Zangaro \& Soeken, 2007). The importance of job satisfaction is underpinned by its status as the most studied organizational variable (Hirschfeld, 2000) in a literature that is "...perhaps the most extensive of all of the management fields" (Lovett, Coyle \& Adams, 2004, p. 217). Low levels of job satisfaction have been associated with increased absenteeism and turnover (Loke, 2001), and may have an adverse impact on patients' and stakeholders' satisfaction.

Zangaro and Soeken (2007) investigated the correlation between job satisfaction and autonomy, collaboration (nurse-physician) and stress. The results of their meta-analysis of 31 studies and over 14,000 respondents revealed that job satisfaction was definitely related to job stress; where the hospital environment and continuous technological change were found to be the main contributors. Regardless of the variables Shader, Broome, Broome, West and Nash (2001) 
argued that job stress leads to job dissatisfaction and augments the probability of high turnover. Other studies have found job satisfaction to be related to tenure with the longer the tenure the less likelihood of turnover (Oshagbemi, 2000; Sarker, Crossman \& Chinmeteepituck, 2003).

Aiken et al. (2001) conducted a study of 43,000 nurses from over 700 hospitals across five countries, finding employee satisfaction with their jobs to be low in Canada (33\%), England (36\%), Scotland (38\%), United States (US) (41\%) with a particularly low result in Germany (17\%). Overall, nurses were not satisfied with work design and management constraints. An alarming finding was that one third of nurses in England and Scotland planned to resign within twelve months of the study, suggesting that job satisfaction may decrease over time. Three hospitals in Taiwan were the sites for Tzeng's (2002) study, which aimed to gather data from 786 nurses employed across all three hospitals. With 82 per cent participation rate Tzeng (2002) concluded that low job satisfaction, poor remuneration and lack of career advancement were high predictors of nurses' intentions to resign from their jobs. In another study of Chinese nurses Wang (2002) found that a high number of nurses were mostly not satisfied with remuneration and job promotion. Moreover, the issues are conducive to deliberative action for improving job satisfaction as a strategy for job retention. In ascertaining predictors of job satisfaction, intrinsic factors embrace effective relationships between physicians and nurses, with their peers and patients (Loke, 2001), motivating work (Manojlovich \& Spence-Laschinger, 2002) and participation in work.

Petrescu and Simmons (2008), claimed that the link between work practices and job satisfaction had been made whereby effective work practices could raise levels of job satisfaction, sometimes to a significant level. Effective practices respond to the many challenges of an organization to ameliorate productivity. Collaboration (such as between nurses and practitioners) has been identified as an important human resource management (HRM) practice that has an important impact on the satisfaction of employees (Pfeffer, 2005; Zangaro \& Soeken, 2007). Other HRM practices (e.g. training, autonomy, participation) act to encourage OCB. In other research, job satisfaction has been hypothesized as a predictor of organizational citizenship behavior (Bell \& Mengue, 2002), Finally, in a study conducted in Taiwan links between HRM practices, JS and OCB have been confirmed (Wei, Han \& Hsu, 2010; Chang, Chen \& Lan, 2011).

\section{Organizational citizenship behavior}

In 1983, Organ and his colleagues (Bateman \& Organ, 1983; Smith, Organ \& Near, 1983) first coined the term organizational citizenship behavior (OCB), also acknowledging that several earlier works (e.g. Barnard, 1938; Roethlisberger \& Dickson, 1939; Katz \& Kahn, 1966) had significantly contributed to an understanding of the underlying principles of the construct. Since the term 'OCB' was introduced, much academic effort has been directed to understanding the construct (e.g. Van Dyne, Graham \& Dienesch, 1994; Organ, 1997). In summery, OCB is distinguishable by a number of key elements: a) the behaviors are spontaneous, discretionary and voluntary in nature as they are not contractually required or directly rewarded by the organization (Meglino \& Korsgaard, 2004; Lester, Meglino and Korsgaard, 2008); and b) in aggregate across individuals and instances, these behaviors are thought to promote the effectiveness of the organization towards which they are directed (Castro, Armario \& Ruiz, 2004; Organ, Podsakoff \& MccKenzie, 2006).

Lester et al., (2008) have suggested that OCB is important in service-oriented organizations. Cohen and Keren (2008) have argued that spontaneous and discretionary behaviors are essential elements in effective service delivery. Through OCB nurses can deliver higher levels of patient 
satisfaction and improve organizational effectiveness (Chang \& Chang, 2009; Lee et al., 2009). Therefore, it is in the interests of healthcare organizations to encourage nurses to engage in OCBs as a means of improving the quality of services (Chang \& Chang, 2010). Coyle-Shapiro, Kessler and Purcell's (2004) study in a UK hospital examined 387 employees' engagement with OCB in response to organizational support and also their engagement as a requirement of the job. Results indicated a strong relationship between OCB and perceived organizational values (Coyle et al., 2004).

Values

Values have long been identified as a key component in the maturity of organizations (Selznick, 1957). Blanchard and O'Connor (1997) argued that firmly held shared values provide the foundations of a successful organization. Conger and Kanungo (1998) extended this viewpoint to argue that shared values are critical to organizational success. Selznik also argued that it is not sufficient just to formulate values; it is essential that these be transmitted to employees as a means of embedding organizational identity and competence, and to engender organizational change. Beyond the development of identity and skills suggested by Selznik, Holtzhausen and Fourie (2009) suggested that communicating values and corporate identity to internal stakeholders is essential in order to achieve goal alignment throughout the organization. Covey (1991) proposed that individual values are a uniting factor when employees are involved in developing organizational values. Given the mix of professional and allied staff in healthcare the formulation of organizational values should involve a multitude of internal groups and stakeholders (Graber \& Kilpatrick, 2008). It follows then that consideration of values in a healthcare context should also involve all organizational members.

Focusing on patient satisfaction with the quality of service, and communicating this to internal customers, assists the organization in the delivery of high quality patient care in a consistent and timely manner (Hallums, 2008). The role of internal customers, such as nurses, is vital in the delivery of high quality service to patients through the services and interactions they provide. Research by Yoon, Choi and Park (2007) suggested that employees will only give their best efforts to satisfy patient needs when internal (i.e. employee) needs are substantially satisfied, therefore job satisfaction is a critical factor in meeting espoused values. Employing and developing staff with a focus on internal operational excellence is a precursor to providing excellent customer service (Vera \& Kuntz, 2007). Values espoused by the hospital in providing quality service to patients are based on a vision of exceptional care provided by exceptional people. In espousing exceptional care the organization is aiming to provide a service to patients that meets or exceeds patients' expectations on all output measures. Such service demands staff that is capable of delivery, a staff comprised of exceptional people. Internalizing the vision to include staff in the process is a key challenge for the organization. Central to the issue of effective internalization is the belief that employee satisfaction leads to increased levels of customer satisfaction (Organ, 1988; Spinelli \& Canavos, 2000; Organ et al., 2006). How employees perceive the degree to which the organization delivers its stated aim of "exceptional service" should be an important factor in actually delivering such service. Discretionary behaviors where staff "goes the extra mile" should also have a positive impact on the service encounter. In an Australian context the study is important given recent media coverage regarding issues of access and long waits for treatment within healthcare (e.g. Cresswell, 2010), together with nurses working in poorly maintained, old facilities while laboring under an increasingly bureaucratic system (Insight, 2011). Achieving effective service delivery is a major challenge for HRM in healthcare. 


\section{Hypotheses Development}

Previous research (e.g. Hirschfeld, 2000; Lu et al., 2004) suggested that, JS is dependent upon each individual and their expectations of the organization and the job, whereas OCB focuses on discretionary behaviors of such individuals beyond any contractual arrangements (e.g. Meglino \& Korsgaard, 2004; Organ, Podsakoff \& MccKenzie, 2006; Lester, Meglino and Korsgaard, 2008). As hospitals depend on the attitudes and behaviors of individual employees for delivery of service quality, JS and OCB are integral components for achieving successful organizational outcomes in hospitals worldwide. Job satisfaction has also been hypothesized as a predictor of OCB (Bell \& Mengue, 2002), suggesting a clear link between the constructs. In addition to JS and OCB, achieving successful organizational outcomes is also dependent on the values shared by an organization and its employees (Selznick, 1957; Blanchard \& O'Connor, 1997, Conger \& Kanungo, 1998).

Job satisfaction is related to turnover with low levels of job satisfaction associated with intention to leave (Zangaro \& Soeken, 2007), with many nurses expressing an intention to leave their jobs early in their careers (Aiken et al., 2001). Research also suggests the longer the tenure of nurses the less likelihood there is of turnover (Oshagbemi, 2000; Sarker et al., 2003). On the basis of the links between JS and turnover, one would assume that satisfied employees would have an increasing desire to maintain membership of the organization as time goes by, providing the hypothesis:

H1. Nurses who are satisfied with their jobs will be less likely to leave the organization as length of service increases.

On the basis of the links between OCB and organizational values discussed above, one should have an increasing desire to maintain membership of the organization as time goes by, providing the hypothesis:

H2. Nurses who engage in OCB will be less likely to leave the organization as length of service increases.

On the basis of the links between JS and organizational values discussed above, one would expect that employees who are satisfied with their jobs would also readily associate with values espoused by the organization. Therefore, we hypothesize the following:

H3. JS will be a positive predictor of the degree to which nurses associate themselves with values espoused by the organization.

Job satisfaction has been shown to be a predictor of OCB. On the basis that employees who engage in discretionary behaviors in the workplace have positive feelings about their work, one would expect that such employees would have an increasing desire to maintain membership of the organization as time goes by, resulting in the following hypothesis:

H4. Nurses who engage in discretionary behaviors at work will be less likely to leave the organization as length of service increases.

Given the links between employee satisfaction and nurses engaging in discretionary behaviors in meeting espoused organizational values (Yoon, Choi \& Park, 2007; Vera \& Kuntz, 2007) we propose the following hypotheses:

H5a. JS will be a significant predictor of the degree to which nurses associate themselves with values espoused by the organization.

H5b. OCB will be a significant predictor of the degree to which nurses associate themselves with values espoused by the organization. 


\section{Methods}

\section{Design}

In this study we used a cross-sectional design to determine if the JS and OCB of nurses were significantly related to organizational values. The study also examined the relationships between JS and OCB with length of service.

\section{Sample}

Eligible participants were 1012 full-time and approximately 945 casual and part-time nurses employed at an Australian hospital. Participants were invited to respond to a hospital-generated questionnaire that was circulated to all employees. Questionnaires, together with envelopes for return when completed, were distributed to all employees on a predetermined date. Sealed boxes were provided for returned questionnaires. Completed questionnaires were removed from sealed boxes and forwarded unopened to a central location for collation and coding. Questionnaires captured data relating to employment status and terms of employment, together with a series of questions designed to determine employee attitudes and behaviors across a range of topics including JS and OCB. Five questions related to the values espoused by the organization (e.g. quality is a core value at this hospital). Questions are detailed in Table 1. Each of the questions invited participants to indicate their response on an interval scale anchored at $1=$ strongly disagree to $5=$ strongly agree.

Table 1:

Construct validity for the measure of values espoused by the organization

\begin{tabular}{lcccc}
\hline & $\begin{array}{l}\text { Item to total } \\
\text { correlation }\end{array}$ & $\begin{array}{l}\text { Cronbach's } \\
\text { alpha if item } \\
\text { removed }\end{array}$ & $\begin{array}{l}\text { Exploratory Factor } \\
\text { Analysis } \\
\text { Factor Load }\end{array}$ & T-Value \\
\hline $\begin{array}{l}\text { There is a spirit of compassion } \\
\text { at this hospital }\end{array}$ & .67 & .86 & .71 & 18.69 \\
$\begin{array}{l}\text { Staff are treated with dignity at } \\
\text { this hospital }\end{array}$ & .68 & .85 & .90 & 18.36 \\
$\begin{array}{l}\text { Quality is a core value at this } \\
\text { hospital }\end{array}$ & .69 & .85 & .87 & 19.29 \\
$\begin{array}{l}\text { Mercy is practiced at this } \\
\text { hospital }\end{array}$ & .75 & .83 & .94 & 21.92 \\
$\begin{array}{l}\text { The hospital demonstrates its } \\
\text { stated values to staff }\end{array}$ & .72 & .84 & .93 & 20.51 \\
\hline
\end{tabular}


Overall 573 of the 1957 nurses employed at the hospital completed the questionnaire, a response rate of $29.3 \%$. The sample was predominantly female $(n=527,92 \%)$, less than two years service $(n=123,20.9 \%)$, two to five years service $(n=151,26 \%)$, six to ten years $(n=125$, $21.4 \%)$ and more than 10 years $(n=174,30 \%)$.

\section{Variables and Measures}

Nurses' job satisfaction and organizational citizenship behaviors were examined using established and extensively validated measures. Organizational values were conceptualized using a measure developed for the study from the questionnaire.

Job satisfaction

Job satisfaction was conceptualized and measured using the short-form of the Minnesota Satisfaction Questionnaire (MSQ), originally developed by Weiss, Dawis, England and Lofquist (1967). Organizational research has shown the 20-item short-form of the MSQ to be a valid and reliable measure of overall job satisfaction, intrinsic job satisfaction and extrinsic job satisfaction (Spector, 1997; Hirschfeld, 2000). An example item from the MSQ is "On my present job this is how I feel about the chance to do things for other people".

Organizational citizenship behavior

Organizational citizenship behavior was conceptualized and measured using scales developed by Podsakoff and Mackenzie (1994) and Moorman and Blakely (1995). An example of an item used in the OCB measure is "There is a spirit of cooperation with one another in this hospital". Organizational citizenship behavior was chosen as it has been shown to be a well-established and valid measure of discretionary behavior (Saari \& Judge, 2004). In a further link between the measures, job satisfaction has been hypothesized as a predictor of organizational citizenship behavior (Bell \& Mengue, 2002), reinforcing an appropriate choice of measures.

Organizational values

Organizational values were conceptualized and measure using a five-item scale developed by the researchers from the questionnaire completed by participants. The questions are detailed in Table 1 above. Reliability and validity of the measure are discussed in the results section below.

\section{Data Analysis}

Data were analyzed using SPSS version 19 software. Preliminary analysis of the data included examination of measures of central tendencies and dispersion, along with visual inspection of the data using histograms, boxplot, skew and kurtosis. The results (see Table 2) indicated that the data were normally distributed. Also, the sample size $(n=573)$ well exceeded the minimum number of cases required for multiple regression analysis (Hair, Anderson, Tatham \& Black, 1998). Before conducting regression analysis a check of outliers was conducted using Mahalanobis distance. Two cases were identified as outliers, which was not unexpected given a sample size of 573. Consequently the outliers were retained in the data set.

Descriptive statistics were used to describe the sample and to assist in answering the research hypotheses. Pearson bivariate correlations were applied to explore the relationships between JS, OCB, and values espoused by the organization. Changes in JS and OCB with length of service were established using One-way ANOVA. Multiple-regression with simultaneous entry of variable was used to establish the impact of independent variables JS and OCB as predictors of the dependent variable for organizational values. The researchers deemed that multiple 
regression analysis was an appropriate means of multivariate analysis given the presence of two independent variables and one dependent variable. As the researcher wished to determine which independent variable had the greatest impact on the dependent variable the simultaneous entry method was used to enter independent variables into the model.

\section{Results}

\section{Descriptives}

Following coding of the questionnaires, descriptive statistics for the following constructs were generated: (a) job satisfaction (JS); (b) discretionary behavior (OCB); and (c) staff perceptions of organizational values (Values). Descriptive statistics and reliability analysis using Coefficient Alpha (Cronbach, 1951) are shown at Table 2 below. The means for JS and OCB were almost

Table 2:

Psychometric Properties of Key Outcome Variables

\begin{tabular}{lccccccccc}
\hline & & & & & & \multicolumn{2}{c}{ Skewness } & \multicolumn{2}{c}{ Kurtosis } \\
\cline { 7 - 10 } Measure & $\mathrm{n}$ & $\mathrm{M}$ & $\mathrm{SD}$ & Alpha & Range & Skew & se & Kurtosis & se \\
\hline JS & 407 & 3.46 & .66 & .92 & $1.00-5.00$ & -.16 & .12 & -.31 & .24 \\
OCB & 497 & 3.47 & .78 & .85 & $1.00-5.00$ & -.24 & .11 & -.41 & .22 \\
Values & 525 & 3.52 & .95 & .87 & $1.00-5.00$ & -.16 & .10 & -.20 & .21 \\
\hline$* p<.05 * * p<.001$ & & & & & & & & &
\end{tabular}

identical, with the mean for values slightly higher. The levels of the means suggested that JS, OCB and perceptions of organizational values were attitudes and behaviors that were strongly held by nurses. Standard deviations (SD) for JS and OCB were within a similar range, while SD for values showed a broader distribution. The degrees of skewness and kurtosis were determined not to be significant, being predominantly within the range of plus or minus twice the standard error of each measure. Skewness and kurtosis, together with measures of central tendency, indicated that the data were normally distributed.

Reliability of the measures was established using Cronbach's alpha (Cronbach, 1951). From the data, reliability for JS at .92 and OCB .85 compared favorably with measures from the seminal JS and OCB research at .91 (Weiss et al., 1967) and .88 (Podsakoff \& Mackenzie, 1994) respectively. Reliability for organizational values showed high reliability with an alpha of .87 , supporting the proposition that it was a reliable measure of the construct.

\section{Univariate}

A one-way between subjects ANOVA was conducted to compare the effect of JS and OCB as independent variables with length of service (less than two years, two to five years, six to 10 years and more than 10 years). Levene's test of homogeneity of variance confirmed that for both variables equality of variance was highly likely, showing no significance at the $\mathrm{p}=.05$ level. Univariate analysis showed there was a significant effect of length of service on OCB at the 
$\mathrm{p}<.05$ level for the four length of service conditions $[\mathrm{F}(3,485)=2.81, \mathrm{p}=.003]$. There was no significant effect of JS on length of service conditions at the $\mathrm{p}<.05$ level for the four conditions $[F(3,395)=0.68, p=.201]$. As there was no significant difference for nurses who are satisfied with their jobs being less likely to leave the organization as length of service increases, Hypothesis 1 was rejected.

Having found a statistically significant result (OCB on length of service) we undertook post hoc comparisons using Tukey's honestly significant different (HSD) test. Tukey's HSD test was used as no significant difference had been indicated by Levene's test as discussed above, indication homogeneity of variance. Post hoc testing indicated that the mean score for less than two years service $(M=3.69, S D=0.72)$ was significantly different $(p=.003)$ to those for six to 10 years $(\mathrm{M}=3.30, \mathrm{SD}=.86)$ and was also significantly different $(\mathrm{p}=.022)$ to the score for more than 10 years service $(\mathrm{M}=3.41, \mathrm{SD}=0.78)$. However, less than two years service was not significantly different to the two to five years service condition. Taken together, these results suggested that nurses' OCB diminished significantly as length of service progressed from six years onwards (i.e. as intention to leave increased). The results were unexpected given previous research suggesting the longer the tenure of nurses the less likelihood there is of turnover (Oshagbemi, 2000; Sarker et al., 2003). Consequently Hypothesis 2 was rejected.

Results of the one-way between subjects ANOVA in respect of JS supported Hypothesis 3, that nurses who are satisfied with their jobs will be less likely to leave the organization as length of service increases, given that no significant difference was noted in JS as length of service progressed. However, results of the one-way between subjects ANOVA in respect of OCB suggested that the tendency of nurses to engage in discretionary behaviors declined with length of service once five years of service had been reached. This was an unexpected result that did not support Hypothesis 4 that nurses who engage in discretionary behaviors at work will be less likely to leave the organization as length of service increases. Therefore, Hypothesis 4 is rejected.

Bivariate

Correlation analysis of the three key variables was conducted in order to establish the level and significance of the relationships between the coefficients. Bivariate correlations are shown at Table 3, below. Intercorrelation between the two predictor variables was found to be high with a coefficient of .88 , and significant $(p<.001)$. Correlations between JS and OCB with the key outcome variable, organizational values, showed high and significant coefficients of .68 ( $\mathrm{p}<.001)$ and $.69(\mathrm{p}<.001)$ respectively.

Table 3:

Summary of bivariate Correlations, Means and Standard Deviations for OCB, JS and perceived organizational values for nurses

\begin{tabular}{lccccc}
\hline Measure & 1 & 2 & 3 & $\mathrm{M}$ & $\mathrm{SD}$ \\
\hline $1 . \mathrm{OCB}$ & - & $.88^{* *}$ & $.69^{* *}$ & 3.46 & .78 \\
2. JS & $.88^{* *}$ & - & $.68^{* *}$ & 3.46 & .66 \\
3. Values & $.69^{* *}$ & $.68^{* *}$ & - & 3.52 &.
\end{tabular}

$* p<.05 * * p<.001$ 


\section{Multivariate}

As the predictor variables were highly correlated, and both were correlated with the outcome variable to a reasonably high level, multiple regression analysis was conducted. A regression model was constructed to test how useful JS and OCB were in predicting positive staff perceptions of organizational values. Given the high correlations between the predictor variables the researchers first tested for multicollinearity using the function provided in SPSS. Results (VIF 4.71, tolerance .21) suggested that multicollinearity was within acceptable bounds. As a further test of multicollinearity the researchers divided the sample into two using the function provided in SPSS. Correlations of the two divided samples for JS and OCB were .88 and .89 respectively, suggesting that the correlations for JS and OCB in respect of the overall sample were representative when the sample was randomly divided. Results of the divided sample confirmed that multicollinearity was with acceptable bounds.

The regression model was constructed with JS, OCB as independent variables and values as the output variable. Significance of the model was confirmed by ANOVA $[F(2,372)=185.82$, $\mathrm{p}<.001]$. The regression model is shown at Table 4 below. The model suggested that JS and OCB together explain 49 percent of the variance in nurses' acceptance of organizational values, which is a highly significant result as indicated by a high $\mathrm{F}$ value in the ANOVA analysis discussed above. The researchers concluded that JS and OCB were reasonably good predictors of how favorably staff accepts the espoused organizational value of "exceptional staff", with OCB being the more important measure. As JS and OCB were significant predictors of acceptance of organizational values Hypotheses $5 \mathrm{a}$ and $5 \mathrm{~b}$ were accepted.

Table 4:

$J S$ and $O C B$ as predictors of organizational values for nurses

\begin{tabular}{|c|c|c|c|c|}
\hline & \multicolumn{4}{|c|}{ JS, OCB as predictors of organizational values } \\
\hline & $\mathrm{b}$ & $\mathrm{SE} \mathrm{b}$ & $\beta$ & $\mathrm{R}^{2}$ \\
\hline Nurses & & & & \\
\hline Constant & .22 & .18 & & \\
\hline JS & .41 & .11 & $.29 * *$ & \\
\hline OCB & .53 & .09 & $.43 * *$ & \\
\hline Adjusted $\mathrm{R}^{2}$ & & & & .49 \\
\hline
\end{tabular}

\section{Reliability and validity}

Reliability and validity for the JS and OCB measures have been established in numerous previous studies (e.g. Weiss et al., 1967; Spector, 1997; Hirschfeld, 2000). Reliability for the measures used in this study, calculated using Cronbach's (1951) alpha, for JS, OCB and values was high $(.92, .85$ and .87 respectively) and is shown in Table 1. 
As the measure for values were developed for this study, tests to confirm validity were conducted and are shown at Table 1. The tests employed were: (a) item to item correlations; (b) Exploratory Factor Analysis; and (c) overall reliability if any of the items were removed from the measure.

Item to total correlations showed that each item of the measure returned high correlation coefficients (.67 to .75) supporting homogeneity of the measure. , Factor analysis returned one factor with an eigenvalue greater than unity (Kaiser, 1958), which accounted for 67 per cent of the total variation. Exploratory Factor Analysis (EFA) showed individual item loadings between .71 and .94, and corresponding t-values greater than the minimum acceptable value of 1.96, (see Table 1), suggesting that construct validity is acceptable (Straub, Boudreau \& Gefen, 2004). Exploratory Factor Analysis also confirmed a good fit with $\chi^{2}(5 \mathrm{df}$., $\mathrm{n}=525)=14.7, \mathrm{p}=.012$. Other outputs resulting from EFA were GFI .99, NFI .99, TLI .98, and CFI .99, all of which exceeded the minimum acceptable value of .95. Also, RMSEA at .06 was below the minimum acceptable value of .08. In addition to an overall measure of reliability, showing Cronbach's alpha of .87, the five items in the measure of values were tested to establish the impact of each item on overall reliability of the measure. Results showed that overall reliability would decrease if any of the items were removed. Testing for item reliability supported the proposition that the measure was valid and reliable.

\section{Discussion}

Analysis indicates a number of important relationships and provides insights in terms of the JS, OCB, and perceptions of organizational values of nurses in an Australian hospital. Significant differences in JS and OCB based on nurses' length of service are observed and these relationships are developed and discussed as challenges for hospital management, supported by HRM. The first of these discussions is centered on nurses' JS, as measured by the MSQ, and their perceptions of organizational values.

In the hospital that provides the context for the research, there is an internal emphasis on developing and supporting employees in a similar way to the patients that the organization and its employees serve. Therefore, it is important for the organization to emphasis its values and to increase the internalization of espoused values with existing employees and those who join the organization. For the organization's approach to be meaningful there needs to be a relationship between espoused values and JS. When the satisfaction of employees is positively developed, one would expect that there would be a corresponding positive increase in OCB. As stated the first item discussed is the finding on JS.

Analysis presented in the previous section indicates a strong relationship between JS and the perceived uptake of organizational values, which are presented in Table 3 . The regression model $\left(\mathrm{R}^{2}=.49\right)$ indicates that JS, with a significant beta of .29 , contributes as a reasonably strong predictor of nurses' internalization of organizational values. The research suggests that JS does not decline significantly over time. What is important for HRM is to recognize that there is a need to maintain high levels of JS amongst nurses in order to ensure that perceptions of organizational values do not decrease.

Analysis also indicates a strong relationship between OCB and the perceived uptake of organizational values, as presented in Table 3. The regression model $\left(\mathrm{R}^{2}=.49\right)$ indicates that OCB with a significant beta value of .43 is a strong predictor of employees' internalization of organization values, being stronger than JS in this regard. Unlike JS discussed above, OCB 
declines significantly as length of service increases. Declining OCB over time is an unexpected finding given previous research of Oshagbemi (2000) and Sarker et al. (2003) that JS increases with length of service. As JS is hypothesized as being a strong predictor of OCB (Bell \& Mengue, 2002) and JS does not show a significant decrease as length of service increases, OCB should also show no significant decrease. The insight from the research with regard to OCB is that early in nurses' careers there is a strong alignment with the values of the organization. The important issue for hospital management, supported by HRM, is to recognize that there is a need to maintain high levels of OCB amongst nurses over time in order to ensure that perceptions of organizational values do not decline. The research suggests that the tendency for nurses to engage less in discretionary behaviors beyond five years of service links directly with the issues that Cresswell (2010) and Insight (2011) raise concerning long waits for treatment, work in poorly maintained and/or old facilities, and the increasing imposts of a bureaucratic system. It is a reflection of dissatisfaction with the 'hygiene' factors associated with nurses' jobs rather than any decrease in the professionalism of primary caregivers.

The relationships between the constructs (JS and OCB), and nurses' perceptions of values espoused by the organization, are important considerations for hospital management. Maintaining high levels of JS and OCB are key challenges for HRM in an organization that wishes its staff to embrace and internalize organizational values. Declining levels of OCB as tenure increases also present challenges for HRM in maintaining or increasing levels. Ongoing development, monitoring of levels of JS and OCB, and training, particularly on an on-going basis as tenure increases, are all areas that could be addressed by HRM. It may be that nurses more readily accept 'hygiene factors' early in their careers, which impacts positively on JS and OCB, yet in respect of discretionary behaviors their acceptance of the work context declines as careers progress. Therefore, investigating the reasons for declining OCB is an important area for future research. By studying the changing nature of OCB over time it may be possible for hospital management to build greater resilience, thus maintaining and then extending the initial positive relationship between JS, OCB and organizational values, as nurses remain within the organization for an extended time. This would allow for a blend of experience with the passion seen in new staff in relation to OCB, therefore improving clinical delivery and organizational reputation.

\section{Conclusion}

A primary focus of hospitals is alignment and internalization of organizational values by nurses. This research provides support for the importance of JS and OCB as predictors of the uptake of organizational values by nurses. Of interest in this study is the identification of declining levels of OCB as tenure increases. The findings establish an important issue for HRM, namely that nurses' OCB declines as tenure increases. The proposition that attitudes and behaviors of employees decline over time is an important area for future research. The study illustrates the importance of perceived organizational values that align with employee attitudes and behaviors.

In conclusion, the research not only provides extended insight into the roles of JS and OCB in conjunction with organizational values, together with implications for HRM, but also identifies a poorly researched and understood area involving length of tenure. Improving understanding of the role of effective organizational values and length of tenure, in conjunction with employee attitudes and behaviors such as JS and OCB, is a challenge for hospital management, supported by HRM. 


\section{References}

Aiken, L., Clarke, S., Sloane, D., Sochalski, J., Busse, R., \& Clarke, H. (2001). Nurses' reports on hospital care in five countries. Health Affairs, 20(3), 43-53.

Ballout, H. (2007). The effects of human capital, person-environment fit and organizational support. Journal of Managerial Psychology, 22(8), 741-765.

Barnard, C. (1938). The functions of the executive. Cambridge, MA: Harvard University Press.

Bateman, S., \& Organ, D. (1983). Job satisfaction and the good soldier: The relationship between affects and employee 'citizenship'. Academy of Management Journal, 26(4), 587-595.

Bell, S., \& Mengue, B. (2002). The employee-organization relationship, organizational citizenship behaviors, and superior service quality. Journal of Retailing, 78(2), 131-146.

Bellou, V. (2010). The role of learning and customer orientation for delivering service quality to patients. Journal of Health Organization and Management, 24(4), 383-395.

Blanchard, K., \& O’Connor, M. (1997). Managing by values. San Francisco: Berrett-Koehler Publishers.

Castro, C., Armario, E., \& Ruiz, D. (2004). The influence of employee organizational citizenship behavior on customer loyalty. International Journal of Service Industry Management, 15(1), 27-53.

Chang, C., \& Chang, H. (2009). Perceptions of internal marketing and organizational commitment by nurses. Journal of Advanced Nursing, 65(1), 92-100.

Chang, C., \& Chang, H. (2010). Motivating nurses' organizational citizenship behaviors by customer-oriented perception for evidence-based practice. Worldviews on EvidenceBased Nursing, 7(4), 214-225.

Chang, C., Chen, S., \& Lan, Y. (2011). Raising nurses' job satisfaction through patient oriented perception and organizational citizenship behaviors. Nursing Research, 60(1), 40-46.

Cohen, A., \& Keren, D. (2008). Individual values and social exchange variables: Examining their relationship to and mutual effect on in-role performance and organizational citizenship behavior. Group and Organization Management, 33(4), 425-452.

Conger, J., \& Kanungo, R. (1998). Charismatic leadership in organizations: perceived behavioral attributes and their measurement. Journal of Organizational Behavior, 15(5), 439-453.

Covey, S. (1991). Principle-centered leadership. New York: Free Press.

Coyle-Shapiro, J., Kessler, I., \& Purcell, J. (2004). Exploring organizationally directed citizenship behavior: Reciprocity or 'It's my job'. Journal of Management Studies, 41(1), 85-106.

Cronbach, L. (1951). Coefficient alpha and the internal structure of tests. Psychometrika, 16, 297-334.

Cresswell, A. (2010). Australia ranks poorly on several measures of access to healthcare. The Australian, June 24, 2010.

Fraenkel, L. \& McGraw, S. (2007). What are the essential elements to enable patient participation in medical decision making. Journal of General Internal Medicine, 22(5), 614-619.

Graber, D., \& Kilpatrick, A. (2008). Establishing values-based leadership in healthcare organizations. Journal of Health and Human Services Administration, 31(2), 179-197.

Hair, J., Anderson, R., Tatham, R., \& Black, W. (1998). Multivariate data analysis. New Jersey: Prentice Hall. 
Hallams, A. (2008). Developing a market orientation. Journal of Nursing Management, 2(2), 8792.

Hirschfeld, R. (2000). Does revising the intrinsic and extrinsic subscales of the Minnesota Satisfaction Questionnaire short form make a difference. Educational and Psychological Measurement, 60(2), 255-270.

Holtzhausen, L., \& Fourie, L. (2009). Employees' perceptions of company value and objectives and employer-employee relationships: A theoretical model. Corporate Communications: An International Journal, 14(3), 333-344.

Insight. (2011). Fixing hospitals. From http://news.sbs.com.au/insight/episode/index/id/ 187\#watchonline

Kaiser, H. (1958). The varimax criterion for analytic rotation in factor analysis. Psychometrika, 23, 187-200.

Katz, D., \& Kahn, R. (1966). The social psychology of organization. New York: Wiley.

Lee, J., Choi, Y., Sung, N., Kim, S., Chung, S., Kim, J., et al. (2009). Development of the Korean primary care assessment tool measuring user experience: Tests of data quality and measurement performance. International journal for quality in Health Care, 21(2), 103111.

Lester, S., Meglino, B., \& Korsgaard, M. (2008). The role of other orientation in organizational citizenship behavior. Journal of Organizational Behavior, 29, 829-841.

Locke, E. (1976). The nature and causes of job satisfaction. In M. Dunnette (Ed.), Handbook of industrial and organizational psychology. Chicago: Rand McNally.

Loke, J. (2001). Leadership behaviors: Effects on job satisfaction, productivity and organizational commitment. Journal of Nursing Management, 9(4), 191-204.

Lu, H., While, A., \& Barriball, K. (2005). Job satisfaction among nurses: A literature review. International Journal of Nursing Studies, 42(2), 211-227.

Lovett, S., Coyle, T., \& Adams, R. (2004). Job satisfaction and technology in Mexico. Journal of World Business, 39, 217-232.

Manojlovich, M., \& Spence-Laschinger, H. (2002). The relationship of empowerment and selected personality characteristics to nursing job satisfaction. Journal of Nursing Administration, 32(11), 586-595.

Meglino, B \& Korsgaard, A. (2004). Considering rational self-interest as a disposition: Organizational implications of other orientation. Journal of Applied Psychology, 89(6), 946-959.

Moorman, R., \& Blakely, G. (1995). Individualism-collectivism as an individual difference predictor of organizational citizenship behavior. Journal of Organizational Behavior, 16(2), 127-142.

Organ, D. (1988). Organizational citizenship behavior: The good soldier syndrome. Lexington, MA: Lexington Books.

Organ, D. (1997). Organizational citizenship behavior: It's construct clean-up time. Human Performance, 10(2), 85-98.

Organ, D., Podsakoff, P., \& MacKenzie, S. (2006). Organizational citizenship behavior: Its nature, antecedents and consequences. Thousand Oaks: Sage.

Oshagbemi, T. (2000). Is length of service related to job satisfaction. International Journal of Social Economics, 27(3), 213-226.

Petrescu, A., \& Simmons, R. (2008). Human resource management practices and workers' job satisfaction. International Journal of Manpower, 29(7), 651-667. 
Pfeffer, J. (2005). Producing sustainable competitive advantage through the efficient management of people. The Academy of Management Executive, 19(4), 95-106.

Podsakoff, P., \& MacKenzie, S. (1994). Organizational citizenship behaviors and sales unit effectiveness. Journal of Marketing Research, 31(3), 351-363.

Podsakoff, P., MacKenzie, S., Paine, J., \& Bachrach, D. (2000). Organizational citizenship behaviors: A critical review of the theoretical and empirical literature and suggestions for future research. Journal of Management, 26, 513-563.

Roethlisberger, R., \& Dickson, W. (1939). Management and the worker. Cambridge, MA: Harvard University Press.

Saari, L., \& Judge, T. (2004). Employee attitudes and job satisfaction. Human Resource Management, 43, 397-407.

Sarker, S., Crossman, A., \& Chinmeteepituck, P. (2003). The relationship of age and length of service with job satisfaction: An examination of hotel employees in Thailand. Journal of Managerial Psychology, 18(7/8), 745-758.

Selznick. P. (1957). Leadership in administration. New York: Harper and Row.

Shader, K., Broome, M., Broome, C., West, M., \& Nash, M. (2001). Factors influencing satisfaction and anticipated turnover for nurses in an academic medical center. Journal of Nursing Administration, 31(4), 26-32.

Smith, C., Organ, D., \& Near, J. (1983). Organizational citizenship behavior: Its nature and antecedents. Journal of Applied Psychology, 68(4), 655-663.

Spector, P. (1997). Job satisfaction: Application, assessment, causes and consequences. Thousand Oaks: Sage.

Spinelli, M., \& Canavos, G. (2000). Investigating the relationship between employee satisfaction and guest satisfaction. Cornell Hotel and Restaurant Administration Quarterly, 41(4), 2933.

Straub, D., Boudreau, M., \& Gefen, D. (2004). Validation guidelines for IS positivist research. Communication of AIS, 13, 380-427.

Tzeng, H. (2002). The influence of nurses' working motivation and job satisfaction on intent to quit: An empirical investigation n Taiwan. International Journal of Nursing Studies, 39(8), 867-878.

Van Dyne, L., Graham, J., \& Dienesch, R. (1994). Organizational citizenship behavior: Construct redefinition, measurement and validation. Academy of Management Journal, 37(4), 765-802.

Vera, A., \& Kuntz, L. (2007). Process-based organization design and hospital efficiency. Health Care Management Review, 32(1), 55-65.

Wang, Y. (2002). Job satisfaction of nurses in hospital. Chinese Journal of Nursing, 37(8), 593594.

Wei, Y., Han, T., \& Hsu, C. (2010). High performance HR practices and OCB: A cross level investigation of a causal path. International journal of Human Resource Management, 21(10), 1631-1648.

Weiss, D., Dawis, R., England, G., \& Lofquist, L. (1967). Manual for the Minnesota Satisfaction Questionnaire. Minneapolis: University of Minnesota, Industrial Relations Center.

Yoon, S., Choi, D., \& Park, J. (2007). Service orientation: Its impact on business performance in the medical service industry. The Service Industries Journal, 27(4), 371-388.

Zangaro, G., \& Soeken, K. (2007). A meta-analysis of nurses' job satisfaction. Research in Nursing and Health, 30(4), 445-458. 